\title{
How Do Community-Dwelling Persons with Alzheimer Disease Fall? Falls in the FINALEX Study
}

\author{
Niko M. Perttila ${ }^{a}$ Hannareeta Öhman ${ }^{a, b}$ Timo E. Strandberg ${ }^{c, d}$ \\ Hannu Kautiainen $^{a}$ Minna Raivio ${ }^{a}$ Marja-Liisa Laakkonen ${ }^{a, b}$ \\ Niina Savikkoc, e Reijo S. Tilvis ${ }^{c}$ Kaisu H. Pitkala ${ }^{a}$ \\ a Department of General Practice and Unit of Primary Health Care, University of Helsinki, \\ Helsinki University Hospital, Helsinki, Finland; ${ }^{b}$ Rehabilitation and Care Services, City \\ Hospital, Helsinki, Finland; ' University of Helsinki, Helsinki University Hospital, Helsinki, \\ Finland; ${ }^{\mathrm{d} C e n t e r}$ for Life Course Health Research, University of Oulu, Oulu, Finland; \\ eElderly Care, Espoo, Finland
}

\author{
Keywords \\ Exercise $\cdot$ Alzheimer disease $\cdot$ Falls
}

\section{Abstract}

Background: People with dementia are at high risk for falls. However, little is known of the features causing falls in Alzheimer disease (AD). Our aim was to investigate how participants with AD fall. Methods: In the FINALEX (Finnish Alzheimer Disease Exercise Trial) study, participants' $(n=194)$ falls were followed up for 1 year by diaries kept by their spouses. Results: The most common reason for falls $(n=355)$ was stumbling $(n=61)$. Of the falls, 123 led to injuries, 50 to emergency department visits, and 13 to fractures. The participants without falls $(n=103)$ were younger and had milder dementia than those with $1(n=34)$ or $\geq 2$ falls $(n=$ 57). Participants with a Mini Mental State Examination score of around 10 points were most prone to fall. In adjusted regression models, good nutritional status, good physical functioning, and use of antihypertensive medication (incident rate ratio [IRR] $0.68,95 \%$ confidence interval [CI] 0.54-0.85) protected against falls, whereas fall history (IRR 2.71, 95\% CI $2.13-$ 3.44), osteoarthritis, diabetes mellitus, chronic obstructive pulmonary disease, higher number of drugs, drugs with anticholinergic properties, psychotropics, and opioids (IRR 4.27, 95\% CI 2.92-6.24) were risk factors for falls. Conclusions: Our study provides a detailed account on how and why people with AD fall, suggesting several risk and protective factors. 


\section{Introduction}

Risk factors for falls have been studied extensively in general older populations. Cognitive impairment and dementia are major risk factors for falls, causing approximately $60 \%$ of older persons with those disorders to fall annually $[1,2]$. Other known risk factors are, for example, history of falls, muscle weakness, gait deficit and deficits, disability, visual deficit, arthritis, depression, older age, polypharmacy and especially psychotropic medications, and environmental hazards [1, 3-7].

There are less studies on risk factors for falls among people with dementia, but older age, female gender, disability and history of falls have been associated with increased risk [8-10]. Furthermore, in a UK study, symptomatic orthostatic hypotension and symptoms of depression were risk factors for falls, whereas higher levels of physical activity appeared to be protective [10]. More severe cognitive decline has been associated with falls [11, 12]. The use of psychotropics has been suggested to be a risk factor for falls $[13,14]$.

Although people with dementia are prone to falls, there has been a paucity of studies investigating prevention of their falls [4]. Only recently did a meta-analysis suggest that exercise has the potential to prevent falls among persons with known cognitive impairment [15].

To our knowledge, studies prospectively exploring the characteristics and consequences of falls among people with dementia are scarce. The FINALEX (Finnish Alzheimer Disease Exercise Trial) study was designed to investigate the efficacy of exercise among participants with Alzheimer disease (AD) [16]. The findings showed that the intervention groups benefitted with respect to falls [16]. The participants with AD were assessed thoroughly at baseline for various risk factors $[16,17]$. Furthermore, during the follow-up year, the participants' spouses kept detailed diaries on falls and their characteristics, which is a highly sensitive method to accurately record falls [18].

The aim of this study was to investigate features of falls among persons with AD over a 1-year follow-up. Furthermore, we tested various known risk factors on how they predict falls during the 1-year follow-up.

\section{Methods}

The original FINALEX study (randomized controlled trial) comprised two active intervention arms: home-based and group-based exercise intervention, both of which were supervised by physiotherapists and consisted of similar exercise components in approximately $1-\mathrm{h}$ sessions held two times a week for 1 year. The control group received normal community care [16]. In this analysis, we investigate all participants (both intervention groups and control group) together to examine features behind the falls. We divided participants into three groups according to the number of falls: none, 1 , and 2 or more falls during the 12-month study period.

\section{Participants}

In 2008, the Social Insurance Institution of Finland used its drug reimbursement register to recruit $\mathrm{AD}$ patients living with a spouse in the cities of Helsinki, Vantaa, or Espoo ( $n=$ 1,264). Altogether 497 persons originally expressed an interest in participating. Study nurses managed to subsequently contact 390 persons, of whom 84 declined to participate and 96 did not fulfill the inclusion criteria: (1) speaking the Finnish language, (2) living with a spouse at home, (3) living in Helsinki, Vantaa, or Espoo, (4) aged $\geq 65$ years, retired, (5) no difficult hemiplegia or diagnosed terminal disease, (6) walking independently with or without a 
mobility aid, and (7) having at least one of the following signs of possible frailty: $\geq 1$ fall during the previous year, unintentional weight loss, or decreased walking speed. A total of 210 patients met our inclusion criteria and were included in the FINALEX study population. Eleven participants declined to participate and 5 died immediately after randomization resulting in 194 participants in this analysis.

The Ethics Committee of Helsinki University Hospital approved the study protocol, and all patients provided informed consent. Spouses provided informed consent if patients had reduced judgment capacity.

Of the 194 participants, 126 were in the intervention groups and 68 in the control group. A detailed description of the intervention has been published in a previous article [17]. Briefly, both intervention arms received $2 \mathrm{~h}$ exercising/week for 1 year supervised by physiotherapists: the home-based group in their own homes and the group-based exercise in day centers in groups of 10 participants. The control group received normal community care and was allowed to receive rehabilitation, including physiotherapy, in the public health care system.

\section{Clinical Measures}

We collected data on demographic factors (age, sex, education) at baseline. Participants' nutritional status was assessed by the Mini Nutritional Assessment (MNA) [19], and their medical records served to confirm their medication and comorbidities; we then calculated the Charlson Comorbidity Index [20]. Cognitive status was evaluated by the Clinical Dementia Rating (CDR) scale [21] and the Mini Mental State Examination (MMSE) [22], and physical functioning was evaluated by the Functional Independence Measure (FIM) [23], the timed "Up and Go" test [24], and the Short Physical Performance Battery (SPPB) [25]. The SPPB includes tests of balance, walking speed, and rise from a chair; we investigated the balance and walking speed tests separately as well as the SPPB test itself [25]. Number of falls during the study is based on the fall diaries kept by the participants' spouses. Fall diaries provided information on the dates and times of falls. The spouses evaluated the reason for a fall. In addition, they stated whether the fall led to injuries, an emergency department or doctor visit, or a fracture. A fall history was assessed by asking the spouses about participants' falls in the year preceding the study.

\section{Statistical Analysis}

Statistical significance for the hypothesis of linearity was evaluated by using analysis of variance (ANOVA) or the Cochran-Armitage test. In case of violation of the assumptions (e.g., non-normality), a bootstrap-type test was used. Fall incidence rates (per 1,000 person-years) with 95\% confidence intervals (CIs) were calculated assuming a Poisson distribution. Adjusted estimates of incidence rate ratios (IRRs) were calculated using Poisson regression models or negative binomial regression models when appropriate. The assumptions of overdispersion in the Poisson model were tested using the Lagrange multiplier test. A nonlinear relationship between the MMSE or number of drugs and incidence of falls was assessed by using Poisson regression, including quadratic terms. STATA 14.1, StataCorp LP (College Station, TX, USA) statistical package was used for the analyses.

\section{Results}

Baseline Characteristics of the Groups with None, One, and Two or More Falls

The baseline characteristics are shown in Table 1 in three groups of fallers: none $(n=$ 103), $1(n=34)$, and 2 or more falls $(n=57)$. The proportion of participants receiving intervention was higher in the groups with none or 1 fall than in those with 2 or more falls, but the 
Table 1. Baseline characteristics

\begin{tabular}{lcccc}
\hline & $\begin{array}{l}0 \text { falls } \\
(n=103)\end{array}$ & $\begin{array}{l}1 \text { fall } \\
(n=34)\end{array}$ & $\begin{array}{l}2 \text { or more falls } \\
(n=57)\end{array}$ & $p$ for linearity \\
\hline Intervention, $n$ (\%) & $70(71)$ & $24(71)$ & $32(56)$ & 0.072 \\
Mean age (SD), years & $77(5)$ & $78(6)$ & $80(4)$ & 0.003 \\
Male sex, $n$ (\%) & $66(64)$ & $14(41)$ & $39(68)$ & 0.84 \\
Education <8 years, $n$ (\%) & $41(40)$ & $15(44)$ & $21(37)$ & 0.77 \\
Mean BMI (SD) & $25.9(3.7)$ & $25.5(3.0)$ & $25.0(3.8)$ & 0.30 \\
Mean MNA (SD) & $23(2)$ & $23(1)$ & $22(3)$ & 0.037 \\
\hline Mean blood pressure (SD), mm Hg & & & \\
$\quad$ Systolic & $153(24)$ & $154(28)$ & $143(27)$ & 0.016 \\
$\quad$ Diastolic & $77(11)$ & $79(13)$ & $74(11)$ & 0.19 \\
Mean Charlson (SD) & $2.6(1.8)$ & $2.7(1.6)$ & $2.9(1.8)$ & 0.22 \\
Mean number of drugs (SD) & $6.1(3.2)$ & $6.9(3.0)$ & $7.0(3.8)$ & 0.12 \\
\hline CDR, $n$ (\%) & $44(43)$ & $12(35)$ & $10(18)$ & $<0.001$ \\
$\quad 0.5-1$ & $47(46)$ & $17(50)$ & $31(54)$ & \\
2 & $12(12)$ & $5(15)$ & $16(28)$ & \\
3 & $92.6(17.3)$ & $92.0(14.0)$ & $77.2(18.6)$ & $<0.001$ \\
Mean FIM total (SD) & $10.2(2.1)$ & $9.7(1.8)$ & $8.7(2.4)$ & $<0.001$ \\
Mean SPPB total (SD) & $6(6)$ & $2(6)$ & $9(16)$ & 0.042 \\
Vision problem, $n$ (\%) & $32(31)$ & $38(24)$ & $35(61)$ & $<0.001$ \\
Fall history, $n$ (\%) & & & \\
\hline
\end{tabular}

SD, standard deviation; BMI, body mass index; MNA, Mini Nutritional Assessment; Charlson, Charlson Comorbidity Index; CDR, Clinical Dementia Rating scale; FIM, Functional Independence Measure; SPPB, Short Physical Performance Battery.

difference did not reach statistical significance. Falls increased with age and the nutritional status was better among those with none or 1 fall than among those with 2 or more falls. Systolic blood pressure was higher in those with none or 1 fall than in those with 2 or more falls. According to the CDR (score of $0.5-1,2$, or 3 ), the severity of dementia was higher among those with 2 or more falls than among those with none or 1 fall. The physical functioning according to FIM scores and SPPB score was higher in those with none or 1 fall than in those with 2 or more falls. There were more participants with vision problems among those with 2 or more falls than among those with none or 1 fall. In the group of 2 or more falls, there were significantly more participants with previous fall(s) than in the other groups. No other significant differences were present in baseline characteristics with respect to the number of falls during the follow-up year.

\section{Description of Falls}

Altogether 355 falls occurred during the follow-up year. Half of them happened at midday. The other half took place equally during mornings, evenings, and at night. The most common reason for a fall was stumbling $(n=61)$, followed by dizziness $(n=37)$, and weakness of legs $(n=18)$. However, in most cases, the spouses were unable to state the reason for falling. Of 355 falls, 123 led to injuries, 50 to emergency department visits, and 13 to fractures.

\section{Risk and Protective Factors for Falls}

Fall history during the preceding year was a strong risk factor for falls (IRR 2.71, 95\% CI 2.13-3.44). Figure 1 shows the associations of the MMSE score and number of drugs with the incidence of falls per person-year (adjusted for age, sex, and intervention). Figure 1a shows 


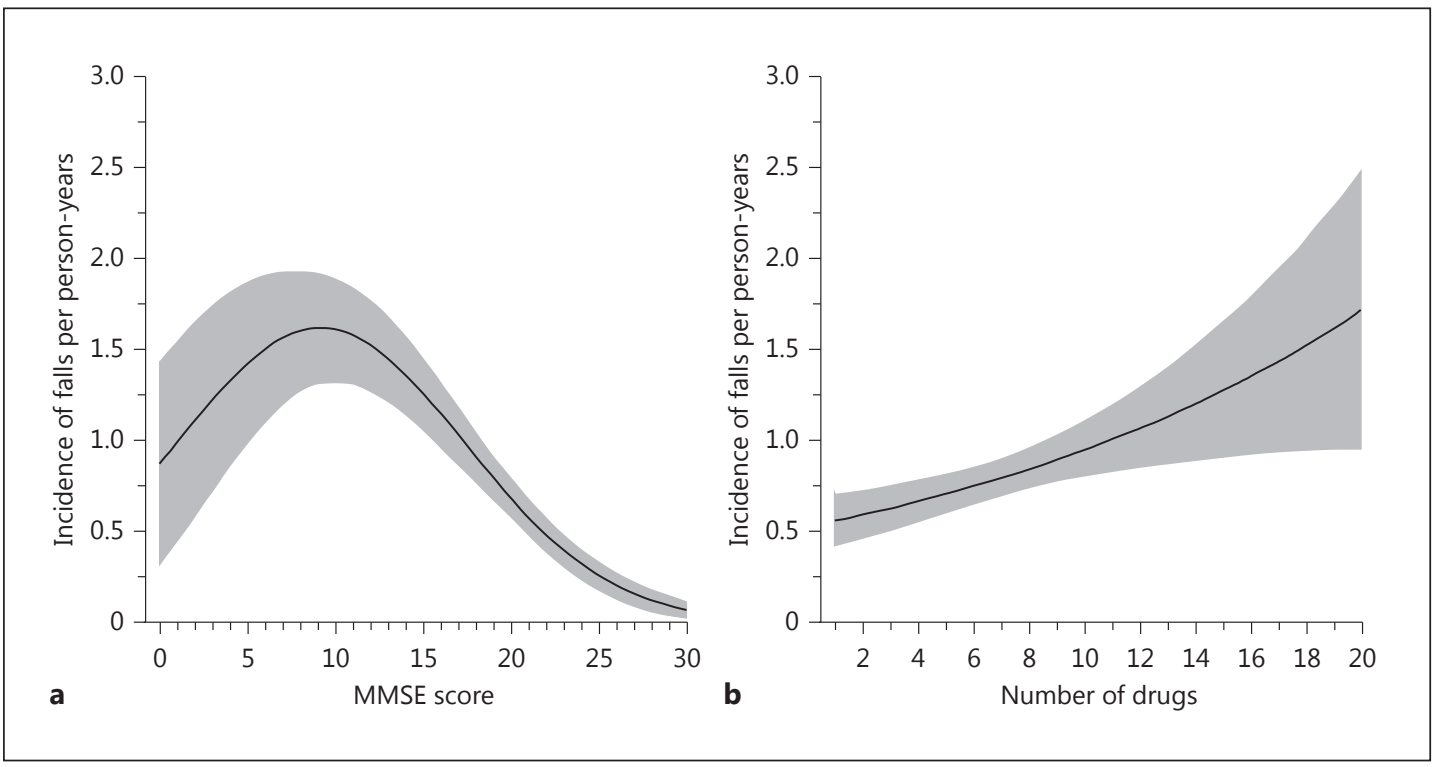

Fig. 1. Mini Mental State Examination (MMSE) score (a) and number of drugs (b) in relation to the incidence of falls per person-years.

that participants with an MMSE score of around 10 points were the most prone to fall. Figure $1 \mathrm{~b}$ reveals that an increasing number of drugs was associated with a higher incidence of falls per person-year.

Figure 2 presents the effects of physical features, diseases, and drugs on the IRRs of falls during follow-up (adjusted for age, sex, and intervention). A better score on all measured physical features (MNA [IRR 0.68, 95\% CI 0.63-0.75], balance test [IRR 0.79, 95\% CI 0.700.88], walking speed [IRR 0.54, 95\% CI 0.48-0.60], SPPB [IRR 0.62, 95\% CI 0.56-0.69], Up and Go test [IRR 0.46, 95\% CI 0.3-0.54], and FIM motor [IRR 0.49, 95\% CI 0.45-0.54]) was associated with a lower IRR of falls. Of the diseases, cancer (IRR 0.56,95\% CI 0.40-0.80) and hypertension (IRR $0.67,95 \%$ CI $0.53-0.85$ ) had a protective association with falls, whereas osteoarthritis (IRR 1.86, 95\% CI 1.31-2.63), diabetes mellitus (IRR 1.59, 95\% CI 1.23-2.06), and chronic obstructive pulmonary disease (COPD; IRR 2.18, 95\% CI 1.33-3.56) increased the IRR. Antihypertensive medication (IRR $0.68,95 \%$ CI $0.54-0.85$ ) had a protective association, whereas drugs with anticholinergic properties (IRR 1.51, 95\% CI 1.19-1.92), psychotropics (IRR 1.69, 95\% CI 1.34-2.12), and opioids (IRR 4.27, 95\% CI 2.92-6.24) increased the IRR.

\section{Discussion}

Our study gives a detailed description on how and why people with AD fall. In our study, traditional protective factors such as good physical functioning and nutritional status were associated with lower number of falls, whereas higher number of drugs, use of drugs with anticholinergic properties, psychotropics, and opioids, as well as osteoarthritis, diabetes, and COPD were positively associated with falls. An unexpected finding was that both hypertension and use of antihypertensive medication were protective factors for falls. People with very low or higher MMSE points were less prone to fall than those with an MMSE point of around 10.

The FINALEX study has several strengths. All participants had a confirmed diagnosis of AD. Falls were assessed by fall diaries kept by spouses. Spousal caregivers continuously filled 


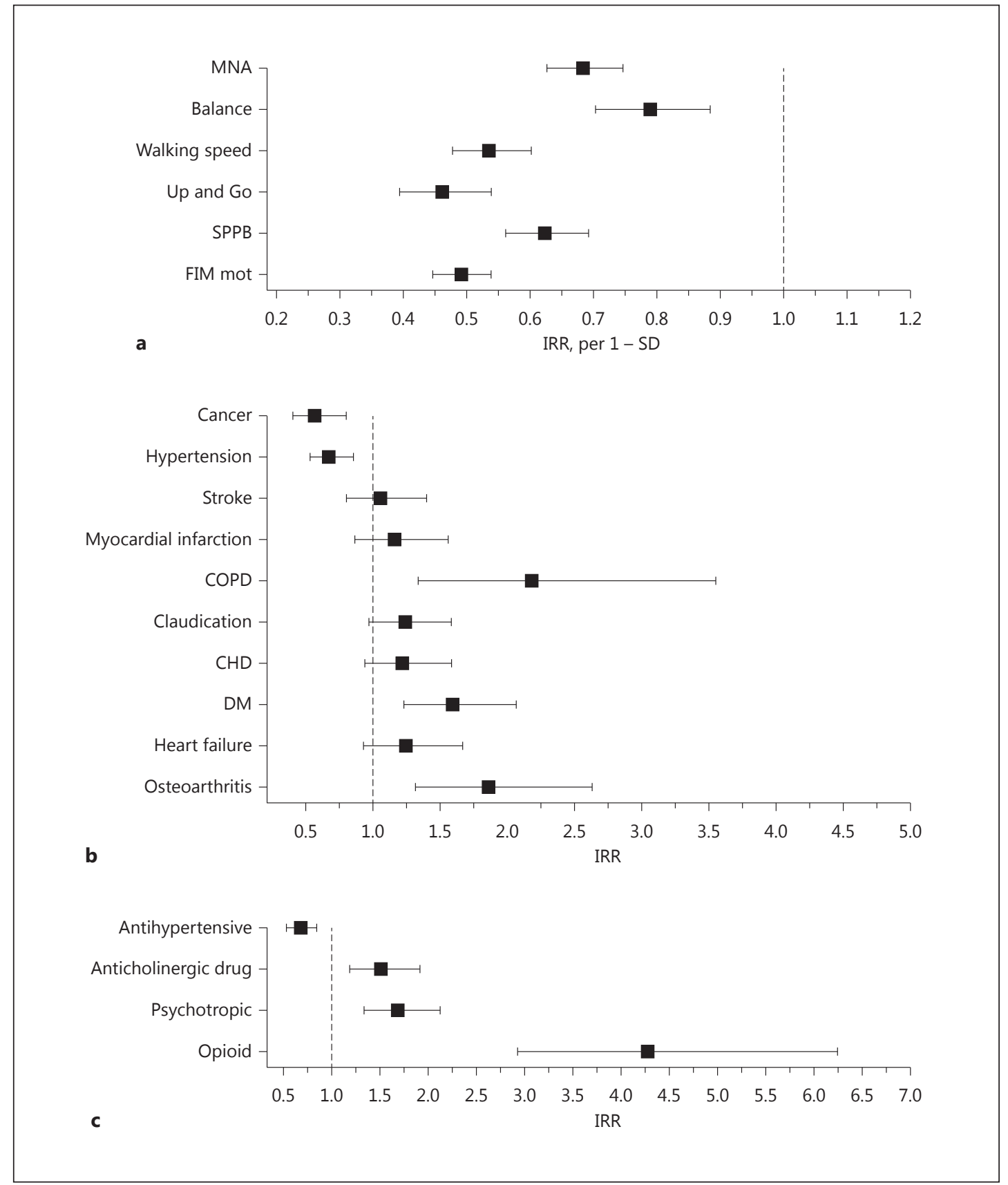

Fig. 2. Effects of physical features (a), diseases (b), and drugs (c) on incidence rate ratios (IRRs) of falls. SD, standard deviation; MNA, Mini Nutritional Assessment; SPPB, Short Physical Performance Battery; Balance, balance test of the SPPB; Walking speed, walking speed test of the SPPB; Up and Go, timed "Up and Go" test; FIM mot, motor part of the Functional Independence Measure; COPD, chronic obstructive pulmonary disease; CHD, coronary heart disease; DM, diabetes mellitus.

in diaries for falls. A diary has been found to be the best method to accurately record falls [18], supporting the reliability of our findings. We investigated the features behind falls in a prospective manner by dividing the participants into three groups (none, 1, and 2 or more falls) based on the falls they experienced during the study. 
This study also has several limitations. The external validity may be questioned since our participants were volunteers for a trial. In addition, all of the participants were living in their homes with their spousal caregivers in the community, and all were Caucasians. Generalization of these results to other populations should therefore be made with appropriate caution. The FINALEX intervention decreased the number of falls in the intervention groups. Thus, the total number of falls in this study is lower than expected among people with AD. This may also have modified the features of their falls. However, our findings were adjusted for age, sex, and intervention considering risk factors for falls. Furthermore, to our knowledge, this is the first study to give a detailed description of falls among AD patients. The number of falls in the control group [16] is in line with previous studies performed among AD patients [10]. This high prevalence suggests that our caregivers have carefully recorded falls.

Some significant differences were present in baseline characteristics between the groups of none, 1 , and 2 or more falls. Persons in the group of 2 or more falls were older. They had poorer nutritional status according to the MNA. Also, their systolic blood pressure was lower than among those with none or only 1 fall. They had more problems with vision. Their stage of dementia was more severe according to the CDR. Also, their physical functioning according to the FIM and mobility limitations according to the SPPB were worse. These characteristics are similar to those found in earlier studies comparing fallers and nonfallers $[8,9,14]$.

Our study is consistent with previous research suggesting that fall history is a risk factor for falls [8-10]. A previous study found that lower MMSE points (in the score range of 22-30) was a risk factor for falling in older persons with subtle cognitive impairment [11]. This is in accordance with our finding in those with higher MMSE scores. However, our study also suggests that persons with MMSE scores of around 10 points are the most prone to falls. Participants with extremely low scores fell less probably because they walk less.

Our study's findings concerning physical functioning, physical activity, and mobility limitations are in line with earlier studies $[3,8,10]$. Higher MNA value served as a protective factor in our study, and previously MNA score has been found to be significantly higher among nonfallers than fallers [8].

Among older persons, polypharmacy and psychotropics have shown strong risk associations with falls [4]. Similar findings emerged in our study; higher numbers of drugs increased the risk of falls. Psychotropics were risk factors for falls, which is in line with other studies on people with dementia $[13,14]$. An important finding here was that the use of opioids showed a high risk for falls. A previous systematic review had found one study in which opioids were associated with falls and one study without this association [26].

In contrast to earlier research [26,27], our study found that both hypertension and antihypertensive medication were protective factors against falls. A UK study had reported symptomatic orthostatic hypotension as a risk factor [10]. The reasons behind our findings remain unclear. These participants with active diagnosis of hypertension and antihypertensives may reflect the same, robust participants having somewhat higher blood pressure whereas those with lower blood pressure may be those with more advanced dementia with a "terminal decline" in their blood pressure [28]. This hypothesis is supported by the fact that those with 2 or more falls had lower blood pressure than those with less falls. However, a recent study among older hypertensive patients suggested that even the frailest patients benefit from antihypertensive drugs [29]. Targeting blood pressure $<120 \mathrm{~mm} \mathrm{Hg}$ improved their prognosis without increasing falls [29].

Our study also found that COPD, diabetes mellitus, and osteoarthritis were risk factors for falls. Arthritis has previously been shown to be a risk factor among older persons [3]. A systematic review and meta-analysis found diabetes to be a risk factor for falls [30], in accordance with our finding among persons with $\mathrm{AD}$. In a study among older women, COPD was a risk factor for falls [31]. These diseases appear to also be risk factors in persons with AD. 


\section{Conclusion}

Individuals with $\mathrm{AD}$ are at high risk for falls, and our study provides a detailed overview on how and why people with AD fall. Results provided support for traditional risk and protective factors behind falls, but also some potentially important, new associations were observed. Antihypertensive drugs and opioids should be explored in future studies to determine whether interactions exist between characteristics of fallers and risk factors.

\section{Acknowledgment}

This work was supported by the Social Insurance Institution of Finland; the Central Union for the Welfare of the Aged; the Sohlberg Foundation; and the King Gustaf V and Queen Victoria Foundation. The sponsors had no role in the study design, data analysis, or interpretation of results, nor did they have a role in writing the report or in the decision to submit it for publication. The authors are independent researchers unassociated with the sponsors.

\section{Disclosure Statement}

The authors have no conflicts of interests to declare.

\section{References}

1 Tinetti ME, Speechley M, Ginter SF: Risk factors for falls among elderly persons living in the community. N Engl J Med 1988;319:1701-1707.

-2 van Dijk PT, Meulenberg OG, van de Sande HJ, Habbema JD: Falls in dementia patients. Gerontologist 1993;33: 200-204.

-3 Guideline for the prevention of falls in older persons. American Geriatrics Society, British Geriatrics Society, and American Academy of Orthopaedic Surgeons Panel on Falls Prevention. J Am Geriatr Soc 2001;49:664672.

4 Panel on Prevention of Falls in Older Persons, American Geriatrics Society and British Geriatrics Society: Summary of the updated American Geriatrics Society/British Geriatrics Society clinical practice guideline for prevention of falls in older persons. J Am Geriatr Soc 2011;59:148-157.

-5 Stalenhoef PA, Diederiks JP, Knottnerus JA, Kester AD, Crebolder HF: A risk model for the prediction of recurrent falls in community-dwelling elderly: a prospective cohort study. J Clin Epidemiol 2002;55:10881094.

6 Campbell AJ, Robertson MC, Gardner MM, Norton RN, Buchner DM: Psychotropic medication withdrawal and a home-based exercise program to prevent falls: a randomized, controlled trial. J Am Geriatr Soc 1999;47: 850-853.

7 Leipzig RM, Cumming RG, Tinetti ME: Drugs and falls in older people: a systematic review and meta-analysis: I. Psychotropic drugs. J Am Geriatr Soc 1999;47:30-39.

-8 Salva A, Roque M, Rojano X, Inzitari M, Andrieu S, Schiffrin EJ, Guigoz Y, Vellas B: Falls and risk factors for falls in community-dwelling adults with dementia (NutriAlz trial). Alzheimer Dis Assoc Disord 2012;26:74-80.

$\checkmark 9$ Meuleners LB, Fraser ML, Bulsara MK, Chow K, Ng JQ: Risk factors for recurrent injurious falls that require hospitalization for older adults with dementia: a population based study. BMC Neurol 2016;16:188.

10 Allan LM, Ballard CG, Rowan EN, Kenny RA: Incidence and prediction of falls in dementia: a prospective study in older people. PLoS One 2009; 4:e5521.

11 Gleason CE, Gangnon RE, Fischer BL, Mahoney JE: Increased risk for falling associated with subtle cognitive impairment: secondary analysis of a randomized clinical trial. Dement Geriatr Cogn Disord 2009;27:557-563.

12 Ohman H, Savikko N, Strandberg T, Kautiainen H, Raivio M, Laakkonen ML, Tilvis R, Pitkala KH: Effects of exercise on functional performance and fall rate in subjects with mild or advanced Alzheimer's disease: secondary analyses of a randomized controlled study. Dement Geriatr Cogn Disord 2016;41:233-241.

13 Kudo Y, Imamura T, Sato A, Endo N: Risk factors for falls in community-dwelling patients with Alzheimer's disease and dementia with Lewy bodies: walking with visuocognitive impairment may cause a fall. Dement Geriatr Cogn Disord 2009;27:139-146. 
14 Horikawa E, Matsui T, Arai H, Seki T, Iwasaki K, Sasaki H: Risk of falls in Alzheimer's disease: a prospective study. Intern Med 2005;44:717-721.

15 Chan WC, Yeung JW, Wong CS, Lam LC, Chung KF, Luk JK, Lee JS, Law AC: Efficacy of physical exercise in preventing falls in older adults with cognitive impairment: a systematic review and meta-analysis. J Am Med Dir Assoc 2015;16:149-154.

-16 Pitkala KH, Poysti MM, Laakkonen ML, Tilvis RS, Savikko N, Kautiainen H, Strandberg TE: Effects of the Finnish Alzheimer Disease Exercise Trial (FINALEX): a randomized controlled trial. JAMA Intern Med 2013;173:894901.

17 Pitkala KH, Raivio MM, Laakkonen ML, Tilvis RS, Kautiainen H, Strandberg TE: Exercise rehabilitation on home-dwelling patients with Alzheimer's disease - a randomized, controlled trial. Study protocol. Trials 2010; 11:92.

18 Hannan MT, Gagnon MM, Aneja J, Jones RN, Cupples LA, Lipsitz LA, Samelson EJ, Leveille SG, Kiel DP: Optimizing the tracking of falls in studies of older participants: comparison of quarterly telephone recall with monthly falls calendars in the MOBILIZE Boston study. Am J Epidemiol 2010;171:1031-1036.

19 Guigoz Y, Lauque S, Vellas BJ: Identifying the elderly at risk for malnutrition. The Mini Nutritional Assessment. Clin Geriatr Med 2002;18:737-757.

20 Charlson ME, Pompei P, Ales KL, MacKenzie CR: A new method of classifying prognostic comorbidity in longitudinal studies: development and validation. J Chronic Dis 1987;40:373-383.

-21 Hughes CP, Berg L, Danziger WL, Coben LA, Martin RL: A new clinical scale for the staging of dementia. Br J Psychiatry 1982;140:566-572.

22 Folstein MF, Folstein SE, McHugh PR: "Mini-mental state." A practical method for grading the cognitive state of patients for the clinician. J Psychiatr Res 1975;12:189-198.

-23 Pollak N, Rheault W, Stoecker JL: Reliability and validity of the FIM for persons aged 80 years and above from a multilevel continuing care retirement community. Arch Phys Med Rehabil 1996;77:1056-1061.

24 Podsiadlo D, Richardson S: The timed "up and go:" a test of basic functional mobility for frail elderly persons. J Am Geriatr Soc 1991;39:142-148.

-25 Guralnik JM, Simonsick EM, Ferrucci L, Glynn RJ, Berkman LF, Blazer DG, Scherr PA, Wallace RB: A short physical performance battery assessing lower extremity function: association with self-reported disability and prediction of mortality and nursing home admission. J Gerontol 1994;49:M85-M94.

-26 Hartikainen S, Lonnroos E, Louhivuori K: Medication as a risk factor for falls: critical systematic review. J Gerontol A Biol Sci Med Sci 2007;62:1172-1181.

-27 Gangavati A, Hajjar I, Quach L, Jones RN, Kiely DK, Gagnon P, Lipsitz LA: Hypertension, orthostatic hypotension, and the risk of falls in a community-dwelling elderly population: the maintenance of balance, independent living, intellect, and zest in the elderly of Boston study. J Am Geriatr Soc 2011;59:383-389.

-28 Benetos A, Bulpitt CJ, Petrovic M, Ungar A, Agabiti Rosei E, Cherubini A, Redon J, Grodzicki T, Dominiczak A, Strandberg T, Mancia G: An expert opinion from the European Society of Hypertension-European Union Geriatric Medicine Society working group on the management of hypertension in very old, frail subjects. Hypertension 2016;67:820-825.

29 Williamson JD, Supiano MA, Applegate WB, Berlowitz DR, Campbell RC, Chertow GM, Fine LJ, Haley WE, Hawfield AT, Ix JH, Kitzman DW, Kostis JB, Krousel-Wood MA, Launer LJ, Oparil S, Rodriguez CJ, Roumie CL, Shorr RI, Sink KM, Wadley VG, Whelton PK, Whittle J, Woolard NF, Wright JT Jr, Pajewski NM; SPRINT Research Group: Intensive versus standard blood pressure control and cardiovascular disease outcomes in adults aged $\geq 75$ years: a randomized clinical trial. JAMA 2016;315:2673-2682.

-30 Yang Y, Hu X, Zhang Q, Zou R: Diabetes mellitus and risk of falls in older adults: a systematic review and metaanalysis. Age Ageing 2016;45:761-767.

-31 Lawlor DA, Patel R, Ebrahim S: Association between falls in elderly women and chronic diseases and drug use: cross sectional study. BMJ 2003;327:712-717. 